J. Clin. Chem. Clin. Biochem.

Vol. 28, 1990, pp. 83-89

(C) 1990 Walter de Gruyter \& Co. Berlin · New York

\title{
Calibration of Direct Reading Photometers for the Determination of Neonatal Bilirubin
}

\author{
By G. Brügmann
}

Hauptlabor der Universitätskinderklinik Tübingen

(Received February 15/October 20, 1989)

Summary: Blijenberg et al. (J. Clin. Chem. Clin. Biochem. 25, 737-741 (1987) (1)) proposed that the assigned values of calibrators for the determination of bilirubin with simple direct reading photometers (bilirubinometers or "bilimeters") should be determined on the same type of instrument. For this purpose, the instrument is calibrated with neonatal serum, whose bilirubin concentration is determined with a reference method unbiased by matrix effects. In the present study, this procedure was developed and tested. Bilirubin was determined in capillary plasma $(n=30)$ and venous serum $(n=31)$ of newborns. Measurements were made by direct spectrophotometry in 4 bilimeters, and by a micromodification of Vink's spectrophotometric method after dilution with caffeine reagent (Vink et al. Clin. Chem. 34, 67-70 (1988) (2)). When the bilimeters were calibrated with a commercial control serum, using the concentrations quoted by the manufacturer, the results were higher by $13 \%$ (plasma) and $19 \%$ (serum) than those obtained by Vink's method. These discrepancies practically disappeared when the bilimeter results were recalculated using a calibrator concentration determined according to Blijenberg. Application of the proposed method to other control sera gave assigned values up to $23 \%$ lower than those stated by the manufacturers. After calibration of the bilimeters with various neonatal sera (specimens drawn for therapeutic purposes and residues, obtained from the clinical laboratory), differences of about $10 \%$ were observed between the assigned values. It is therefore essential to use several sera. Minor differences were found between bilimeters. Practically the same results were obtained using either the procedure of Vink et al. (2) or Doumas et al. (Clin. Chem. 31, 1779-1789 (1985) (3)) as the reference method. Blijenberg's procedure can help to reduce interlaboratory imprecision in neontal bilirubin analysis.

\section{Introduction}

Even with the introduction of transcutaneous measurement, the photometric determination of neonatal bilirubin is still frequently necessary. Direct spectrophotometry of capillary plasma in simple photometers built for this purpose is especially practicable. According to Kupke (4), the method is precise and accurate. On the basis of our own experience, the precision of the method is satisfactory. The accuracy of the method, however, is problematic. Differences have been reported between the results obtained in different laboratories by direct photometry in interlaboratory surveys, as well as for individual samples, and between the results of direct photometry and chemical methods in the same laboratory $(1,5-7)$. In the present study, therefore, the analytical values for patient sera were determined on 4 bilimeters and compared with the results from a more demanding spectrophotometric method. Furthermore, we redetermined the assigned values of certain commercial products for the calibration and monitoring of bilimeters, using the method proposed by Blijenberg et al. in the discussion to their later studies on the standardization of neonatal bilirubin (1). 


\section{Materials and Methods}

\section{Patient samples}

Samples from newborns, which had been received by the laboratory for routine investigation, were used for the method comparison ( 30 venous sera and 31 capillary plasma samples from haematocrit tubes). After measurement in the bilimeters, capillary plasma was removed from the haematocrit capillaries for analysis by Vink's method. Each patient sample was investigated only once, and comparative measurements were performed on the same sample. The following samples were used for determination of the assigned values of commercial control samples and calibrators: pool $\mathrm{A}$, which consisted of the residues of 19 neonatal sera from the routine laboratory, sera $1-6$ from 6 neonatal blood samples taken for therapeutic purposes, and pool B, which consisted of equal parts of sera 3-6. None of these samples showed visible haemolysis. For the estimation of haemoglobin spectra were recorded during the analysis by Vink's method. They were compared with spectra obtained under the same conditions from Sta-Bil with and without addition of haemolysate. These estimated concentrations of haemoglobin were $0.01-0.05 \mathrm{mmol} / \mathrm{l}$ in sera $1-6,0.02 \mathrm{mmol} / \mathrm{l}$ in pool $\mathrm{A}$, and $0.03 \mathrm{mmol} / \mathrm{l}$ in pool $\mathrm{B}$.

\section{Control samples and calibrators}

Assigned values for bilimeters were determined for the following products (supplier and matrix in brackets): Sta-Bil (Baxter, D8044 Unterschleißheim; human albumin solution), Kontrollogen (Behring, D-3550 Marburg; human albumin solution), Precibil (Boehringer, D-6800 Mannheim; human serum), Ultimate bilirubin calibrators and controls (Beckman, D-8000 München; human serum with addition of ethylene glycol). Batch numbers are given with the results. Bilirubin standards (Lot Nos. 850723 and 850726) from RIVM, NL-3720 BA Bilthoven, as well as a $1: 2$ dilution of Sta-Bil BIC 975 with physiological saline were used to test the linearity of the bilimeters.

\section{Reagents}

Reagents were obtained from Merck, D-6100 Darmstadt, and from Fluka, $\mathrm{CH}-9470$ Buchs.

\section{Bilirubin determination by direct spectropho-} tometry

Samples were placed in haematocrit capillaries, and their absorbance measured at $455 \mathrm{~nm}$ and $575 \mathrm{~nm}$ in 4 bilimeters (Molter, D-6903 Neckargemünd). For the measurement of patient samples, the bilimeters were calibrated with Sta-Bil BIC 975 , using the assigned values quoted by the manufacturer. The coefficient of variation between days was $2.1 \%$. At the beginning of the investigation, two of the four bilimeters were new from the factory, and the other two were older models which had been recently serviced by the manufacturer.

\section{Comparative methods}

The following two methods for bilirubin determination are largely independent of the matrix.

Method of Vink et al. (2): $50 \mu$ l of sample were mixed with $1.35 \mathrm{ml}$ of caffeine reagent, and the difference in absorbance at 465 and $528 \mathrm{~nm}$ was measured. The coefficient of variation within series was $1.6 \%$ when the sample was delivered by running from the pipette against the vessel wall. By washing the pipette contents into the reagent solution, the coefficient of variation within series was decreased to $0.5 \%$ (sera 3-6 in table 2 , and the analysis by Vink's method in table 4). For patient samples, a micromodification of the method $(7 \mu \mathrm{l} \mathrm{sam-}$ ple $+200 \mu$ l reagent) was used (coefficient of variation within series $1.2 \%$ ).
The method of Doumas et al. (3), recommended as a reference method, is similar to the procedure of Jendrassik \& Groff, and it is very exacting with respect to reagents, timing and spectrophotometer $(598 \mathrm{~nm})$ performance. To obtain the data in table 2 , the volumes were decreased to $50 \%$ of those in the original method, or to $20 \%$ (from serum 3 onwards); the coefficients of variation within series were 1.2 and $1 \%$, respectively.

Absorbance was measured in a model PU 8700 spectrophotometer (Philips, D-3500 Kassel) with a $2 \mathrm{~nm}$ bandwidth. Results were calculated using the factors published by the authors.

\section{Volumetric apparatus}

Citopipettes (Bühler, D-7400 Tübingen) and Dispensettes (Brand, D-6980 Wertheim) were used for volumes greater than $500 \mu$ l, Eppendorf pipettes (Netheler \& Hinz, D-2000 Hamburg) for $50-500 \mu \mathrm{l}$, and a SMI pipette (Pabisch, D-8000 München) for $7 \mu$ l. Each delivery system was tested either gravimetrically or photometrically, and the volumes determined in this way were used in the calculation of the analytical result.

\section{Statistics}

The data quoted for precision apply to individual determinations at a concentration of $300 \mu \mathrm{mol} / \mathrm{l}$. Regression lines were calculated by the method of Deming (8). The ratio of the error variances of the two methods was assumed to be 1 . Analyses of variance (three-way classifications, fixed effects) were performed by the usual procedures (9).

\section{Method comparison on patient samples}

Determinations performed in duplicate (except for 2 samples of capillary blood), using the micromodification of Vink's method, and the mean values of the individual measurements from 4 bilimeters were used for the comparison. The regression parameters for each bilimeter are given in order to estimate the variance of results within the 4 machines.

Determination of assigned values for calibrators and control sera for use in bilimeters according to Blijenberg (1)

Neonatal sera and serum pools derived from them were used for the calibration of the bilimeters. The bilirubin concentrations of these samples and pools were determined several times by the methods of Vink et al. and Doumas et al. The bilirubin concentrations measured subsequently in commercial products are the assigned values to be used for the calibration or monitoring of bilimeters during their routine operation.

\section{Results}

The results obtained with Vink's method and with the bilimeters are compared in figure 1 and table 1 .

To test the linearitiy of the bilimeters, 4 machines were calibrated with the bilirubin standard containing $290 \mu \mathrm{mol} / 1$. Subsequent analysis of a standard containing $99 \mu \mathrm{mol} / 1$ showed errors between $+1.4 \%$ and $+7.8 \%$ (mean $4.3 \%$ ). A similar result was obtained for the analysis of undiluted and diluted Sta-Bil (error between $+2.6 \%$ and $+10 \%$, mean $+5.2 \%)$. 


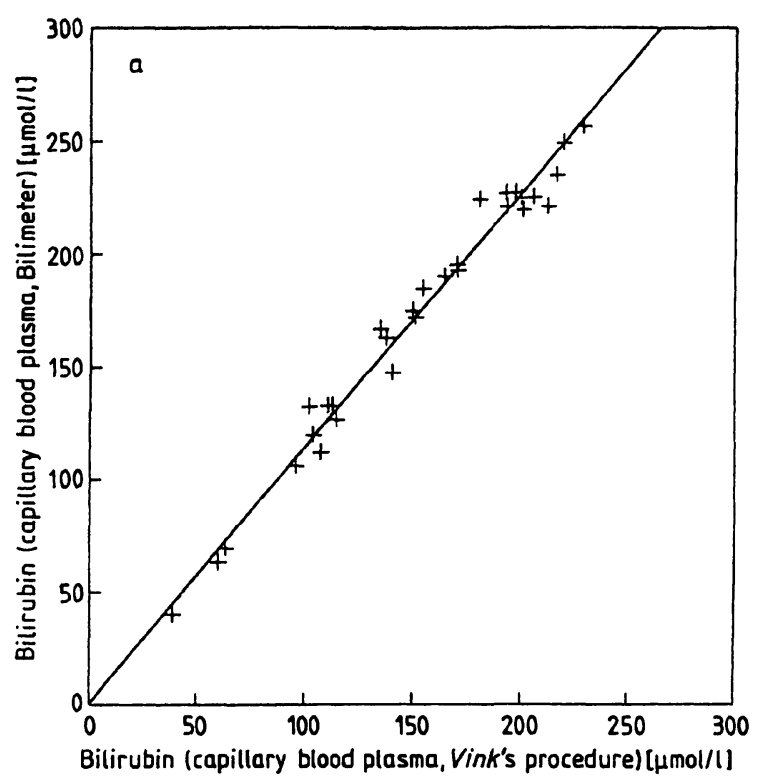

Fig. 1. Comparison of analytical results obtained on the bilimeters with those obtained by Vink's spectrophotometric method. The bilimeters were calibrated with Sta-Bil

Tab. 1. Intercepts $(\mathrm{aO})$ and slopes (a1) of the regression lines from fig. 1 ( $a$ and $b$ ).

\begin{tabular}{lcclll}
\hline $\begin{array}{l}\mathrm{x}=\text { Vink's } \\
\text { method } \\
\mathrm{y}=\end{array}$ & \multicolumn{2}{l}{$\begin{array}{l}\text { Capillary plasma, } \\
\mathrm{n}=30\end{array}$} & \multicolumn{3}{l}{$\begin{array}{l}\text { Venous serum, } \\
\mathrm{n}=31\end{array}$} \\
\cline { 2 - 3 } & $\mathrm{a} 0(\mu \mathrm{mol} / \mathrm{l})$ & $\mathrm{a} 1$ & & $\mathrm{a} 0(\mu \mathrm{mol} / \mathrm{l})$ & $\mathrm{a} 1$ \\
\hline $\begin{array}{l}\text { Bilimeter } \\
\text { average }\end{array}$ & 0.5 & 1.13 & & -0.6 & 1.19 \\
Bilimeter 1 & -1.1 & 1.14 & & -1.4 & 1.21 \\
Bilimeter 2 & 0.5 & 1.12 & -4.3 & 1.21 \\
Bilimeter 2 & -3.6 & 1.18 & & -0.0 & 1.19 \\
Bilimeter 3 & 5.3 & 1.11 & 2.7 & 1.17 \\
\hline
\end{tabular}

Bilirubin concentrations of the neonatal sera used for calibration are shown in table 2 . The average values obtained by the methods of Vink et al. and Doumas et al. were used for the subsequent calculations. In addition to the analyses by Vink's method reported in tables 3 and 4 , four of the investigated control sera were also analysed several times by Doumas' method. The differences between the two methods were less than $2 \%$ of the mean value.

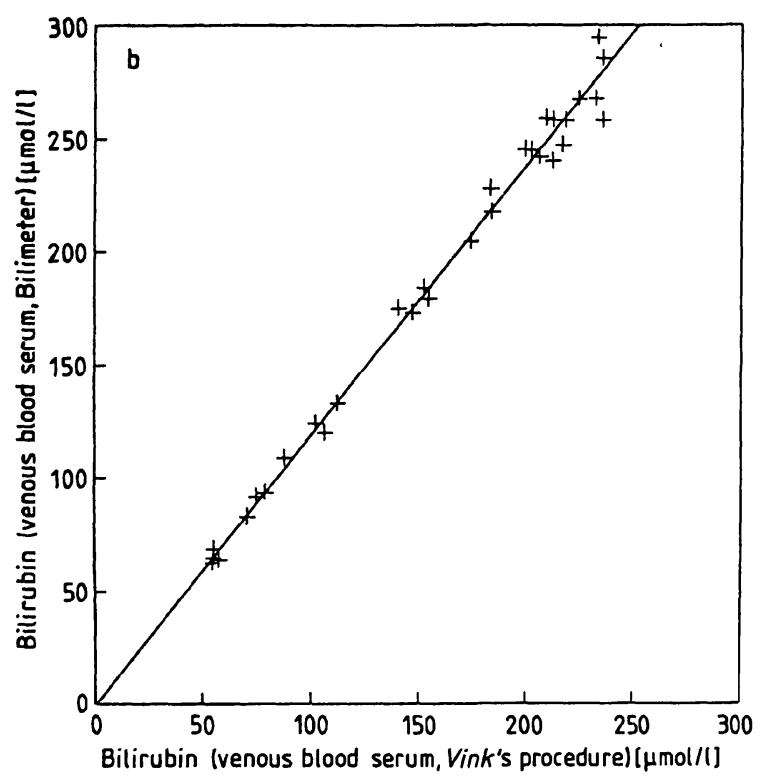

BIC 975, using the manufacturer's assigned value.

a) Capillary plasma $(r=0.989)$.

b) Venous serum $(r=0.995)$.

The data summarized in table 3 were obtained by using sera 1 and 2 as calibrators for the determination of the assigned values of some commercial control and standard sera. At the same time, assigned values for Sta-Bil BIC $976(250 \mu \mathrm{mol} / \mathrm{l})$ and Sta-Bil BIC 977 $(243 \mu \mathrm{mol} / \mathrm{l})$ were measured after calibration of the bilimeters with pool A. The deviation of these values from those quoted by the manufacturer for use with the bilimeter were $-22 \%$ and $-26 \%$, respectively, i.e. the deviations were considerably greater than those shown in table 3. Additional serum samples were therefore collected (samples 3-6) and used both individually and as a pool for the determination of assigned values (tab. 4). Determination of assigned values and analysis by Vink's method were performed concomitantly. Comparisons of these results with the values supplied by the manufacturer for use with bilimeters (when available) and for use with the Jendrassik-Gróf method are shown in tables 3 and 4. These two tables also show the differences (when determined for more than 2 sera or more than 2 bilimeters, these are the maximal differences) between

Tab. 2. Bilirubin determination $[\mu \mathrm{mol} / \mathrm{l}]$ in the neonatal sera used as calibrators.

\begin{tabular}{|c|c|c|c|c|c|c|c|c|c|c|}
\hline $\begin{array}{l}\text { Analytical } \\
\text { method }\end{array}$ & & Pool A & $\begin{array}{l}\text { Serum } \\
1\end{array}$ & $\begin{array}{l}\text { Serum } \\
2\end{array}$ & $\begin{array}{l}\text { Serum } \\
3\end{array}$ & $\begin{array}{l}\text { Serum } \\
4\end{array}$ & $\begin{array}{l}\text { Serum } \\
5\end{array}$ & $\begin{array}{l}\text { Serum } \\
6\end{array}$ & $\begin{array}{l}\text { Mean } \\
\text { of sera } \\
3-6\end{array}$ & $\begin{array}{l}\text { Pool B } \\
\text { from sera } \\
3-6\end{array}$ \\
\hline Vink et al. & $\begin{array}{l}\mathrm{n} \\
\overline{\mathrm{x}} \\
\text { S.D. }\end{array}$ & $\begin{array}{r}9 \\
118.3 \\
7.2\end{array}$ & $\begin{array}{r}13 \\
71.6 \\
2.3\end{array}$ & $\begin{array}{r}27 \\
139.3 \\
4.4\end{array}$ & $\begin{array}{c}6 \\
162.0 \\
10.1\end{array}$ & $\begin{array}{r}6 \\
257.8 \\
1.2\end{array}$ & $\begin{array}{r}6 \\
139.8 \\
1.0\end{array}$ & $\begin{array}{r}6 \\
197.1 \\
1.3\end{array}$ & 189.2 & $\begin{array}{r}6 \\
188.3 \\
1.0\end{array}$ \\
\hline Doumas et al. & $\begin{array}{l}\text { n } \\
\bar{x} \\
\text { S.D. }\end{array}$ & $\begin{array}{r}4 \\
106.2 \\
2.6\end{array}$ & $\begin{array}{c}4 \\
70.8 \\
0.9\end{array}$ & $\begin{array}{r}4 \\
141.6 \\
1.3\end{array}$ & $\begin{array}{r}5 \\
163.6 \\
3.8\end{array}$ & $\begin{array}{c}5 \\
264 \\
1.8\end{array}$ & $\begin{array}{r}5 \\
142.5 \\
1.8\end{array}$ & $\begin{array}{r}5 \\
201.6 \\
2.5\end{array}$ & 193.0 & $\begin{array}{c}6 \\
193 \\
3.7\end{array}$ \\
\hline
\end{tabular}


Tab. 3. Determination of assigned values in control sera 1988. Concentrations and differences are given in $\mu \mathrm{mol} / \mathrm{l}$. Percentage differences between the sera and bilimeters, and between the experimental values and those quoted by the manufacturers are given in italics. Sta-Bil BIC 976 and 977 were investigated on 2 bilimeters, all other control sera on 4 bilimeters.

\begin{tabular}{|c|c|c|c|c|c|}
\hline \multirow[t]{3}{*}{ Control serum } & \multirow{3}{*}{$\begin{array}{l}\text { Assigned } \\
\text { values } \\
\text { of the } \\
\text { manufac- } \\
\text { turer }\end{array}$} & \multirow{3}{*}{$\begin{array}{l}\text { Analysis according } \\
\text { to Vink et al. } \\
1988\end{array}$} & \multicolumn{3}{|c|}{$\begin{array}{l}\text { Determination of assigned values on bilimeters after calibration } \\
\text { with sera } 1 \text { and } 2\end{array}$} \\
\hline & & & \multirow[t]{2}{*}{$\overline{\text { Mean }}$} & \multicolumn{2}{|c|}{ Maximal difference between } \\
\hline & & & & Sera & Bilimeters \\
\hline Sta-Bil BIC 975 & & 313.0 & 278.6 & 10.4 & 13.5 \\
\hline Bilimeter & 332 & $-5.7 \%$ & $-16.1 \%$ & $3.1 \%$ & $4.1 \%$ \\
\hline Jendrassik \& Gróf & 318 & $-1.6 \%$ & $-12.4 \%$ & $3.3 \%$ & $4.2 \%$ \\
\hline Sta-Bil BIC 976 & & 337.4 & 292 & 5.7 & 10 \\
\hline Bilimeter & 321 & $5.1 \%$ & $-9.0 \%$ & $1.8 \%$ & $3.1 \%$ \\
\hline Jendrassik \& Gróf & 352 & $-4.1 \%$ & $-17.0 \%$ & $1.6 \%$ & $2.8 \%$ \\
\hline Sta-Bil BIC 977 & & 325.4 & 284.5 & 5.4 & 1.6 \\
\hline Bilimeter & 330 & $-1.4 \%$ & $-13.8 \%$ & $1.6 \%$ & $0.5 \%$ \\
\hline Jendrassik \& Gróf & 342 & $-4.9 \%$ & $-16.8 \%$ & $1.6 \%$ & $0.5 \%$ \\
\hline Kontrollogen 613415 & & 336.5 & 282.4 & 8.7 & 12.6 \\
\hline Jendrassik \& Gróf & 354 & $-4.9 \%$ & $-20.2 \%$ & $2.5 \%$ & $3.5 \%$ \\
\hline Precibil 157908 & & 277.0 & 260.2 & 8.0 & 9.2 \\
\hline Jendrassik \& Gróf & 282 & $-1.8 \%$ & $-7.7 \%$ & $2.8 \%$ & $3.2 \%$ \\
\hline
\end{tabular}

Tab. 4. Determination of assigned values in control sera 1989. Concentrations and differences are given in $\mu$ mol/l. Percentage differences between sera and bilimeters, and between the experimental values and those quoted by the manufacturers are given in italics. All control sera were investigated on 2 bilimeters.

\begin{tabular}{|c|c|c|c|c|c|c|}
\hline \multirow[t]{3}{*}{ Control serum } & \multirow{3}{*}{$\begin{array}{l}\text { Assigned } \\
\text { values } \\
\text { of the } \\
\text { manufac- } \\
\text { turer }\end{array}$} & \multirow{3}{*}{$\begin{array}{l}\text { Analysis } \\
\text { according } \\
\text { to Vink et al. } \\
1989\end{array}$} & \multicolumn{4}{|c|}{$\begin{array}{l}\text { Determination of assigned values on bilimeters after calibration } \\
\text { with sera } 3-6\end{array}$} \\
\hline & & & \multirow{2}{*}{$\begin{array}{l}\text { Individual } \\
\text { sera. } \\
\text { Mean }\end{array}$} & \multirow[t]{2}{*}{ Pool B } & \multicolumn{2}{|l|}{ Difference } \\
\hline & & & & & $\begin{array}{l}\text { Serum } 6- \\
\text { serum } 4\end{array}$ & $\begin{array}{l}\text { Bilimeter } \\
\text { old }- \text { new }\end{array}$ \\
\hline Sta-Bil BIC 976 & & 333.74 & 306.7 & 296.4 & 30.76 & 5.30 \\
\hline Bilimeter & 321 & $4.0 \%$ & $-4.5 \%$ & $-7.7 \%$ & $9.6 \%$ & $1.7 \%$ \\
\hline Jendrassik \& Gróf & 352 & $-5.2 \%$ & $-12.9 \%$ & $-15.8 \%$ & $8.7 \%$ & $1.5 \%$ \\
\hline Sta-Bil BIC 977 & & 321.83 & 300.2 & 290.1 & 30.10 & 7.05 \\
\hline Bilimeter & 330 & $-2.5 \%$ & $-9.0 \%$ & $-12.1 \%$ & $9.1 \%$ & $2.1 \%$ \\
\hline Jendrassik \& Gróf & 342 & $-5.9 \%$ & $-12.2 \%$ & $-15.2 \%$ & $8.8 \%$ & $2.1 \%$ \\
\hline Kontrollogen 613415 & & 324.26 & 282.4 & 273.0 & 28.33 & 10.23 \\
\hline Jendrassik \& Gróf & 354 & $-8.4 \%$ & $-20.2 \%$ & $-22.9 \%$ & $8.0 \%$ & $2.9 \%$ \\
\hline Precibil 157473 & & 284.43 & 296.8 & 286.9 & 29.74 & 5.36 \\
\hline Jendrassik \& Gróf & 330 & $-13.8 \%$ & $-10.1 \%$ & $-13.1 \%$ & $9.0 \%$ & $1.6 \%$ \\
\hline Ultimate C8 M802172 & & 125.15 & 122.1 & 118.1 & 12.21 & -4.51 \\
\hline Jendrassik \& Gróf & 126.5 & $-1.1 \%$ & $-3.5 \%$ & $-6.7 \%$ & $9.7 \%$ & $-3.6 \%$ \\
\hline Ultimate C20 M807147 & & 318.18 & 306.6 & 296.3 & 30.72 & 9.74 \\
\hline Jendrassik \& Gróf & 327.3 & $-2.8 \%$ & $-6.3 \%$ & $-9.5 \%$ & $9.4 \%$ & $3.0 \%$ \\
\hline Ultimate D2 M809047 & & 97.99 & 97.0 & 93.8 & 9.73 & -7.63 \\
\hline Jendrassik \& Gróf & 103 & $-4.9 \%$ & $-5.8 \%$ & $-9.0 \%$ & $9.4 \%$ & $-7.4 \%$ \\
\hline Ultimate D3 M803143 & & 141.42 & 142.7 & 138.0 & 14.28 & -1.93 \\
\hline Jendrassik \& Gróf & 145 & $-2.5 \%$ & $-1.6 \%$ & $-4.8 \%$ & $9.8 \%$ & $-1.3 \%$ \\
\hline Ultimate D4 M811130 & & 269.80 & 265.4 & 256.5 & 26.60 & 2.97 \\
\hline Jendrassik \& Gróf & 284 & $-5.0 \%$ & $-6.6 \%$ & $-9.7 \%$ & $9.4 \%$ & $1.0 \%$ \\
\hline
\end{tabular}


the assigned values, when these were determined with different sera (mean for all bilimeters) or with different bilimeters (mean for all sera).

Analyses of variance were performed on the results from the 4 bilimeters shown in table 3 , and on the results for sera 3-6 shown in table 4 . Both serum and bilimeter made a significant $(p<0.01)$ contribution to variance.

\section{Discussion}

The correlation between the results from the bilimeters and those from Vink's method was satisfactory.

Intercepts $(\mathrm{aO})$ are small. The slopes (a1) show that the bilimeters, when calibrated in the conventional way, give mean values that are $13 \%$ higher (capillary plasma) and $19 \%$ higher (venous serum) than the reference method (tab. 1). Similar results were reported by Blijenberg (1). Although individual bilimeters show different slopes, these are in practice largely compensated by deviations in the intercepts. Thus, simply by correction of the assigned value of the calibrator, the differences between the results from the bilimeters and the reference method can be reduced, so that they are well within clinically acceptable limits.

To perform this correction, the assigned values of commercial sera were determined by Blijenberg's proposed method (1) (tab. 3 and 4). On average, the determined values were very different from those quoted by the manufacturer, and the extent of this difference depended strongly on the particular product. Considerable differences were also found between different batches from the same manufacturer. Values quoted for bilimeters did not always show smaller differences to the new assigned values than those given for the method of Jendrassik \& Gróf (Sta-Bil BIC 975, tab. 3). It should be noted that the deviation of the regression coefficient from 1 in the comparison of methods with patient samples (tab. 1) could have been abolished on average by using the new assigned value for Sta-Bil BIC 975 (tab. 3) for calibration of the bilimeters.

Special attention must be paid to the following factors, which can influence the determination of the assigned values by Blijenberg's method.

1) Reference analyses. In this study predetermined constants are used in the calculation of the bilirubin concentration from the analytical data. A standardized procedure is therefore necessary, with high-performance, properly calibrated photometers and vol- umetric apparatus. Particularly in the case of bilirubin analysis, it is probably easier to obtain reproducible results by attention to these details than by using calibrators. With one exception (pool A in tab. 2), there were no significant differences between the results from Vink's and Doumas' methods. If this good agreement is confirmed in subsequent investigations, it would be possible to simplify the determination of assigned values by using only Vink's method. In this connection, the findings of Hajzer (10) are of interest, although he used a calibrator for Vink's method and a decreased proportion of sample for Doumas' method. His graphs show that individual results may differ by up to $8 \%$ of the mean values from the two methods.

2) The neonatal sera used for calibration. Both variance analyses showed a significant contribution from the serum. The differences between sera 1 and 2 shown in table 3 , however, represent only $2-3 \%$ of the assigned value, and are therefore of no practical importance. On the other hand, the differences between sera 4 and 6 shown in table 4 are about $9 \%$ of the assigned value, and therefore cannot be ignored. The mean assigned values after calibration with individual sera 3-6 differ by only about $+3 \%$ from those obtained after calibration with pool B (tab. 4). The use of pools for calibration is therefore feasible. In contrast, after calibration with pool A, the results showed wide deviations. There were also striking differences between the values for pool A determined by Vink's and Doumas' methods (tab. 2). In view of the observed scatter between the sera and the possibility of outliers, it is absolutely necessary to use several neonatal sera or pools thereof for the determination of utilizable assigned values.

3) The bilimeters. Although the bilimeter makes a statistically significant contribution to variance, the experimentally determined differences are relatively unimportant. It is, however, worth noting that the sign of this difference changes, depending on whether the analysed sample is a control serum with a high bilirubin concentration, or a product with a low bilirubin concentration (tab. 4). This effect is possibly explained by different deviations from linearity of the calibration curves of the two machines. The neonatal sera needed for the method, prepared from therapeutic blood samples or residues from laboratory routine, should contain between 100 and $200 \mu \mathrm{mol} / \mathrm{l}$ bilirubin. The assigned values determined with such samples are optimally suitable for the determination of values in the decision range for or against phototherapy. To minimize the influence of deviations from linearity of the bilimeters on the proposed determination of as- 
Tab. 5. Comparison of the results of the present work with the assigned values reported by Schlebusch et al. (11). Concentrations are given in $\mu \mathrm{mol} / \mathrm{l}$. Percentage differences between the experimental values and those quoted by the manufacturer are given in italics.

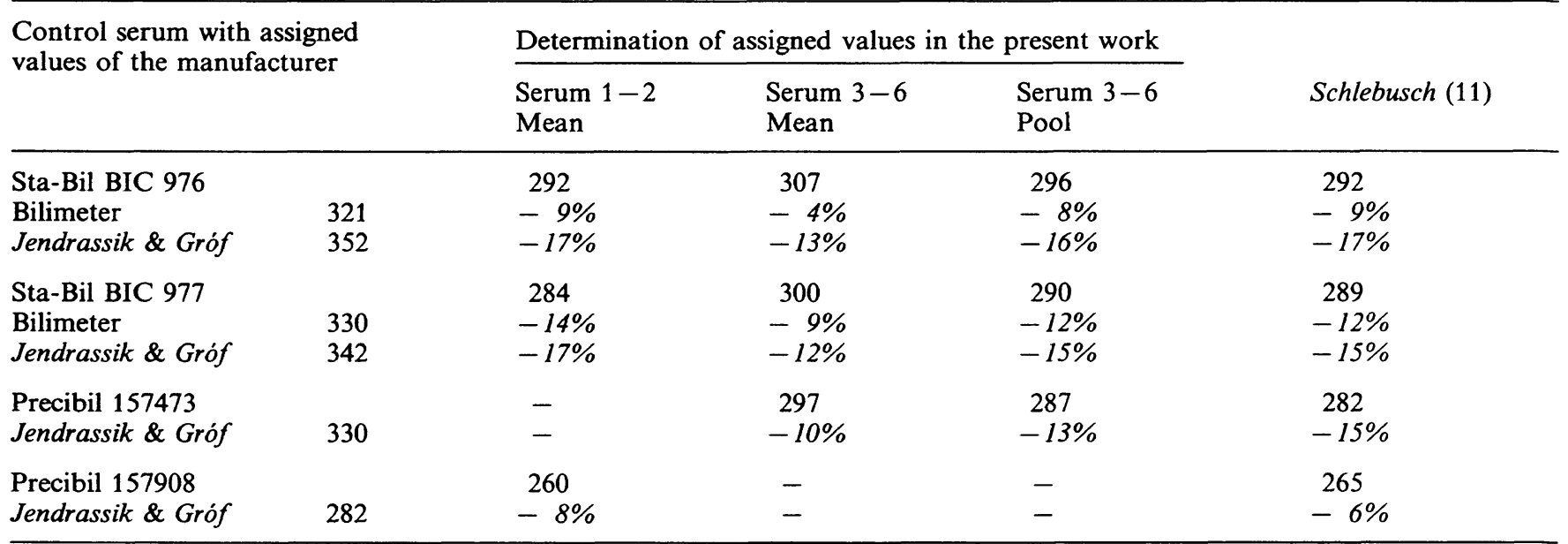

signed values, it would obviously be advantageous to also use calibrator concentrations in this range for routine work. Appreciable errors would then only occur at concentrations around $300 \mu \mathrm{mol} / \mathrm{l}$; due to the use of phototherapy, such concentrations of bilirubin are seldom observed. These errors are easy to determine for each apparatus. For the bilimeters used in the present work they lie between $-1 \%$ and $-8 \%$.

Three measures would influence the bilimeter results in the same direction as the method proposed by Blijenberg. The results given in tables 3 and 4 for the analysis of control sera by Vink's method are lower than the values quoted by the manufacturers. The use of Vink's method for assigned value determination, however, would not on its own solve the special problems of bilimeter calibration. The same is true when the calibrator concentration is lower than $200 \mu \mathrm{mol} / \mathrm{l}$; the effect of such a change of calibrator concentration depends on the linearity of the bilimeter used for the determination. Finally, tables 3 and 4 show that the deviations are definitely lower for products based on human sera, especially if the manufacturer's value is replaced by that determined by Vink's method. This finding should be confirmed by the investigation of further batches of the products in question.

Schlebusch et al. (11) have also determined the assigned values of 5 commercial control and calibration sera, using the method proposed by Blijenberg. Ten individual sera, 2 pools (each comprising 5 sera), and a mixture of both pools were analysed by Vink's method and on a bilimeter. The value determined for each mixture was the same as that calculated from its components. The assigned values determined with the aid of the combined pools are in close overall agreement with the results of the present work (tab. 5). The bilimeter used in Schlebusch's determination showed a greater deviation from linearity than the machines used in the present investigation (fig. 1 in l.c. (11)).

Universal introduction of the proposed method for the determination of assigned values of calibrators and control samples for bilimeters would greatly improve the comparability of the analytical results from different laboratories. The effect on variance of using different neonatal sera and pools thereof for calibration purposes must be examined further. The variance between bilimeters also requires further study. It could be reduced by using controls and calibrators with bilirubin concentrations in the linear range of the apparatus. An effort should also be made to extensively standardize the reference method.

\section{Acknowledgement}

We are grateful to the firms of Baxter and Beckman for the gift of control and calibrator sera, to Dr. U. Umpfenbach (Krefeld) for supplying serum 3, and to Mrs. Regina Kusyschyn (Tübingen) for skilful and dedicated technical assistance. 


\section{References}

1. Blijenberg, B. G., Roetering, H. A., de Vos, A. \& Leijnse, B. (1987) Further Studies on the Standardization of Neonatal Bilirubin. J. Clin. Chem. Clin. Biochem. 25, 737741.

2. Vink, K. L. J., Schuurman, W. \& van Gansewinkel, R. (1988) Direct Spectrophotometry of Bilirubin in Serum of the Newborn, with Use of Caffeine Reagent. Clin. Chem. $34,67-70$.

3. Doumas, B. T., Kwok-Cheung, P. P., Perry, B. W., Jendrzejczak, B., McComb, R. B., Schaffer, R. \& Hause, L. L. (1985) Candidate Reference Method for Determination of Total Bilirubin in Serum: Development and Validation. Clin. Chem. 31, 1779-1789.

4. Kupke, I. R. (1977) Die Photometrische Mikrobestimmung von Bilirubin im unverdünnten Kapillarplasma von Neugeborenen. Z. Geburtsh. Perinat. 181, 456-459.

5. Blijenberg, B. G., Roetering, H. A. \& Leijnse, B. (1987) Reflections on the Standardisation of Total Bilirubin in Neonatal Serum. J. Clin. Chem. Clin. Biochem. 25, 177181. This paper contains references to other studies by the same authors.

6. Röhle, G., Schlebusch, H., Geilenkeuser, W. J. \& Kruse, R. (1988) External Quality Control in the Determination of Neonatal Bilirubin. An Approach to the Improvement of Results. J. Clin. Chem. Clin. Biochem. 26, 441-446.

7. Brügmann, G. (1988) Zur Kalibrierung der Bilirubinbestimmung bei Neugeborenen. J. Clin. Chem. Clin. Biochem. 26 737-738.

8. Cornbleet, P. J. \& Gochman, N. (1979) Incorrect LeastSquares Regression Coefficients in Method Comparison Analysis. Clin. Chem. 25, 432-438.

9. Rasch, D. (1970) Einführung in die mathematische Statistik, 2. Auflage, VEB Deutscher Verlag der Wissenschaften, Berlin 1970.

10. Hajzer, S. (1989) Comparison of Direct Spectrophotometric Determinations of Bilirubin with Candiate Reference Method in Sera of Newborns. J. Clin. Chem. Clin. Biochem. 27, 445-449. See also Schlebusch, H. (1990) Letter to the Editor. J. Clin. Chem. Clin. Biochem. 28, 121-122.

11. Schlebusch, H., Liappis, N., Röhle, G. \& Schneider, Ch. (1989) Zur Kalibration von Bilirubinometern. Lab. Med. $13,364-368$.

Dr. Gerd Brügmann

Universitäts-Kinderklinik

Rümelinstraße 23

D-7400 Tübingen 
